\title{
Role of the Renin-Angiotensin System in Cardiovascular Disease
}

\author{
Jay N. Cohn
}

Published online: 8 May 2010

(C) Springer Science+Business Media, LLC 2010

Cardiovascular disease has a long natural history that begins pathophysiologically with endothelial dysfunction resulting in impaired bioactivity of nitric oxide [1] (Fig. 1). The progression of disease in the artery wall and in the left ventricular myocardium may be associated with elevated blood pressure and is characterized by structural changes in the arteries, especially those perfusing the myocardium, brain, kidneys and the lower extremities [2]. This atherosclerotic process, especially if accompanied by hypertension, also causes progressive structural changes in the left ventricle that may result in heart failure, arrhythmias and sudden death [3].

Aging and atherosclerosis produce similar vascular and cardiac changes with small and large artery wall thickening and loss of ventricular myocytes [4, 5]. Plaque formation, rupture and clot formation are unique to the atherosclerotic process and account for most myocardial infarctions and strokes [6].

\section{RAS activation}

The renin-angiotensin system (RAS) plays an important role in the progression of the cardiovascular changes of aging and atherosclerosis. Angiotensin contributes to endothelial dysfunction [7], which facilitates the process, and angiotensin is a potent stimulator of vascular smooth muscle and myocyte growth [8]. Furthermore, the vasoconstrictor effect of angiotensin raises blood pressure,

\footnotetext{
J. N. Cohn $(\bowtie)$

Department of Medicine, Cardiovascular Division, University of Minnesota Medical School,

Mayo Mail Code 508, 420 Delaware Street Southeast, Minneapolis, MN 55455, USA

e-mail: cohnx001@umn.edu
}

which adds a pressure-mediated influence on vascular smooth muscle and myocardial growth and remodeling [9].

Activation of the RAS with elevation of plasma renin activity (PRA) is a common finding in cardiovascular diseases (CVD). Whether the activation is genetically determined, is a manifestation of impaired renal perfusion, is a consequence of the disease itself, or is a resultant of therapy such as diuretics or ACE inhibitors commonly employed in CVD, is unclear. Nevertheless, the magnitude of RAS activity bears a direct relationship to subsequent morbidity and mortality. PRA has been shown to be associated with the incidence of acute MI [10], mortality and hospitalization in patients with heart failure [11, 12], morbid events and mortality in post-infarction patients [13] and with mortality in the Framingham population [14]. In V-HeFT II, the Vasodilator Heart Failure Trial, PRA at baseline was a significant predictor of subsequent mortality, regardless of assigned therapy [11]. In the SOLVD trial PRA was modestly elevated in patients with asymptomatic left ventricular dysfunction and strikingly elevated in those with Class II or III heart failure [15]. Thus disease severity and disease mortality appear to be directly related to PRA.

\section{Inhibition of the RAS}

Interest in the deleterious effects of the renin-angiotensin system has been stimulated by the availability of welltolerated drugs that can inhibit the system at three independent sites (Fig. 2). Demonstration that chronic administration of these drugs can prevent morbid events and prolong life in patients with established cardiovascular disease has further documented the adverse role of the renin-angiotensin system (RAS) in disease progression [1621]. Unresolved is whether an activated RAS is necessary 


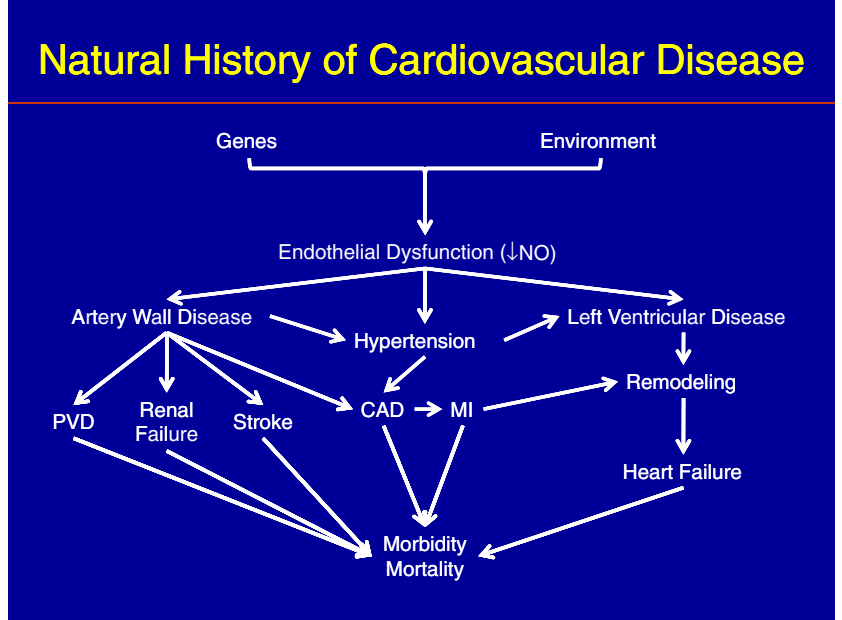

Fig. 1 The natural history of cardiovascular disease begins with genetic and environmental factors causing endothelial dysfunction. Vascular and cardiac structural abnormalities result from the impairment of nitric oxide bioactivity and are aggravated by hypertension and myocardial dysfunction related to coronary disease

for the benefit of RAS inhibition, or whether unstimulated RAS activity can be further inhibited to improve outcome. Since an activated RAS has not been a prerequisite in any of these trials it cannot be determined if RAS activation is necessary for the beneficial response to therapy.

The simplest means of assessing RAS activity is the measurement of plasma activity of the system. Plasma renin activity (PRA) is a measurement of the in vitro rate of formation of angiotensin I from its substrate, a process which is dependent on renin [22]. Circulating angiotensin II, the end-product of the RAS, is far more difficult and

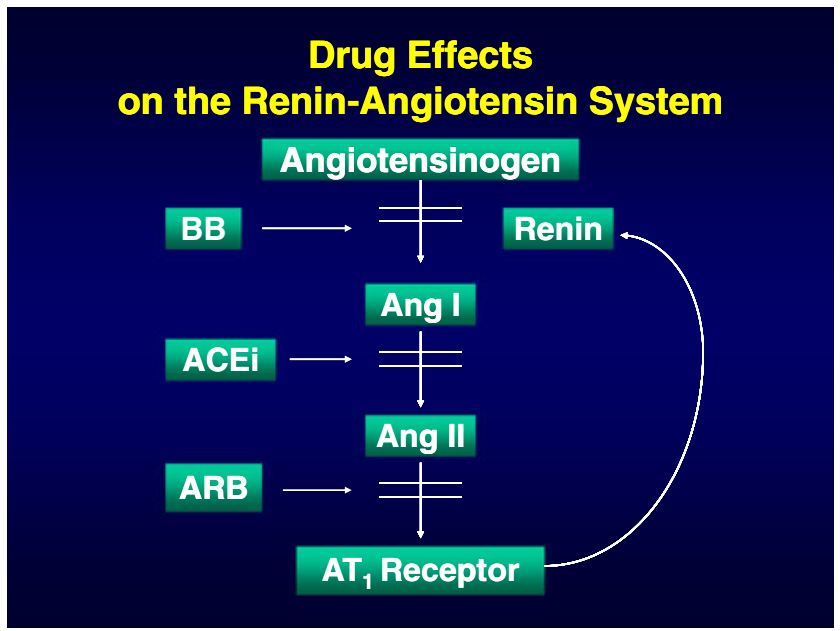

Fig. 2 The cascade of angiotensin formation can be inhibited at three steps: (1) beta blockers (BB) and direct renin inhibitors (DRI) that interfere with renin activity and angtiotensin I generation; (2) angiotensin converting enzyme inhibitors (ACEI) that block the formation of angiotensin II; and (3) angiotensin receptor blockers (ARB) that block the effect of angiotensin II. Reduced angiotensin II activity results in a positive feedback stimulation of renin generation tedious to assay but provides a more direct measurement of activity of the hormone system [23].

\section{Biochemical cascade}

The biochemical cascade resulting in formation of the active hormone angiotensin II and its biologic effects provides opportunity for inhibition of the system at several different sites. Angiotensin converting enzyme (ACE) inhibitors block the formation of the octopeptide angiotensin II from its decapeptide precursor, angiotensin I. The biochemical markers for this effect are increases in angiotensin I, decreases in angiotensin II, and stimulation of renin activity which results from a decrease in angiotensin II activity.

Activation of renin in response to ACE inhibitors leads to excessive production of angiotensin I. In the absence of complete inhibition of ACE activity, which is rarely achieved with clinical dosing of ACE inhibitors, the excess angiotensin I results in formation of angiotensin II that may restore angiotensin II levels despite the continuing administration of an ACE inhibitor. Although this angiotensin II formation may partially suppress the renin stimulation of chronic ACE inhibitor therapy, the net result may be some restoration of angiotensin II levels despite continued therapy with an ACE inhibitor.

The dose of ACE inhibitor would be expected to be a factor influencing renin stimulation. Furthermore, it might be expected that PRA would cease to be a useful prognostic marker in the presence of ACE inhibitor therapy. In Val-HeFT,

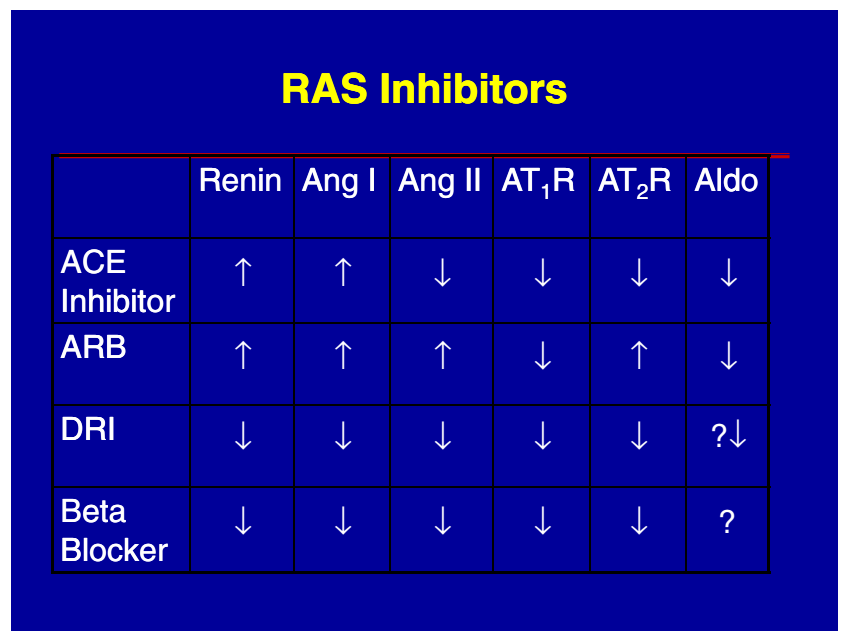

Fig. 3 Components of the biochemical cascade of the reninangiotensin system are differentially affected by inhibitors. The influence of these drugs on renin activity, angiotensin I levels, angiotensin II levels, AT1 receptor activity, AT2 receptor activity, and aldosterone levels are displayed by arrows 
a trial of the angiotensin receptor blocker, valsartan, patients were maintained during the trial on the ACE inhibitor dose they were receiving at baseline. As predicted, those taking an ACE inhibitor had higher PRA activity than those not receiving an ACE inhibitor, and the level of PRA was directly related to the ACE inhibitor dose [24]. Nonetheless, baseline PRA remained an independent predictor of mortality despite the influence of ACE inhibitors on the baseline level. Thus underlying renin activity is a determinant of PRA, even in the presence of ACE inhibitors, and this renin activity remains a powerful influence on mortality.

Beta blockers, although not generally thought of as inhibitors of the RAS, are powerful inhibitors of renal renin secretion, which is stimulated by beta-1 receptors. Concomitant administration of a beta blocker with an ACE inhibitor results in striking suppression of the reninstimulating effect of ACE inhibitors [25]. Since current recommended therapy for heart failure is a combination of ACE inhibitor and beta blocker it is likely that RAS activation is not as great a concern in chronic heart failure than it may have been in the past. Indeed, the striking mortality reduction when beta blockers are added to ACE inhibitors in heart failure [26-28] may in part be related to the renin-inhibiting effect of beta blockers.

Angiotensin receptor blockers (ARB) have become an attractive replacement for ACE inhibitors in recent years because of their remarkable freedom from side effects. These drugs block specifically the angiotensin II (AT1) receptors which subserve the vasoconstrictor and adverse tissue effects of angiotensin. Left unopposed and, in fact stimulated, are the AT2 receptors which may subserve vasodilation and tissue protection. Since ARBs block receptor activation they also promote stimulation of renin that leads to rises in PRA. Higher doses of ARBs can inhibit receptor activation even from heightened circulating levels of angiotensin II.

A direct renin inhibitor, aliskiren, is now marketed for hypertension and represents a fourth pharmacologic mechanism of inhibiting RAS activity. Preliminary studies suggest that it may also prove to be effective in treatment of heart failure [29]. The observation that it has additive effects to ACE inhibitor or ARB dosing [30] is consistent with prior studies suggesting additive benefits when an ARB is added to an ACE inhibitor. The failure of additive benefit in a post-MI population [31] or in a population with atherosclerosis [32] has tempered the enthusiasm for combining two or three RAS inhibitors to achieve greater clinical benefit. As shown in Fig. 3, however, these drugs all produce a different pattern of pharmacologic inhibition and their combination is therefore not necessarily redundant. Further studies are needed to determine the optimal patients and optimal dosing of combination therapy to achieve better outcomes.

\section{Clinical application}

Drugs that inhibit the RAS have become the most widely used agents to treat cardiovascular disease. They lower blood pressure, preserve serum $\mathrm{K}+$ levels that may be dangerously reduced by diuretic therapy, and produce favorable effects on vascular and cardiac structure. Suppression of ventricular growth and remodeling [33] may be a critical factor in their beneficial effect on hypertension and heart failure [34].

Monitoring of RAS activity, as a possible guide to disease severity and as a potential guide to the need for RAS inhibition, has not been recommended. Current methods for assessing RAS activity are cumbersome and greatly influenced by background therapy and management. A simpler means of assessing RAS activity might allow determination of its clinical usefulness in selecting patients for RAS-inhibiting therapy. Is atherosclerotic disease dependent for its progression on heightened activity of the RAS, or is the RAS, much like LDL cholesterol levels, continuously related to disease progression so that the response rate to treatment is similar at all baseline levels of activity? Until these issues are clarified, these drugs alone or in combination are likely to continue to be the drugs of choice to protect all patients with known cardiovascular disease. Their use in asymptomatic patients to slow disease progression $[35,36]$ is a potential preventative application that may come to characterize future cardiovascular therapy.

\section{References}

1. Perticone F, Ceravolo R, Pujia A, et al. Prognostic significance of endothelial dysfunction in hypertensive patients. Circulation. 2001;104:191-6.

2. Unger $T$. The role of the renin-angiotensin system in the development of cardiovascular disease. Am J Cardiol. 2002;89 (suppl):3A-10.

3. Dahlof B, Pennert K, Hansson L. Reversal of left ventricular hypertrophy in hypertensive patients - a meta-analysis of 109 treatment studies. Am J Hypertens. 1992;5:95-110.

4. Lakatta EG, Levy D. Arterial and cardiac aging: major shareholders in cardiovascular disease enterprises: part I: aging arteries: a "set up" for vascular disease. Circulation. 2003;107:139-46.

5. Olivetti G, Melissari M, Capasso JM, Anversa P. Cardiomyopathy of the aging human heart. Myocyte loss and reactive cellular hypertrophy. Circ Res. 1991;68:1560-8.

6. Ferrario CM, Strawn WB. Role of the renin-angiotensinaldosterone system and proinflammatory mediators in cardiovascular disease. Am J Cardiol. 2006;98:121-8.

7. Girouard H, Park L, Anrather J, Zhou P, Iadecola C. Angiotensin II attenuates endothelium-dependent responses in the cerebral microcirculation through nox-2-derived radicals. Arterioscler Thromb Vasc Biol. 2006;26:826-32.

8. Schmidt-Ott KM, Kagiyama S, Phillips MI. The multiple actions of angiotensin II in atherosclerosis. Regul Pept. 2000;93:65-77. 
9. Thurmann PA, Kenedi P, Schmidt A, et al. Influence of the Angiotensin II antagonist valsartan on left ventricular hypertrophy in patients with essential hypertension. Circulation. 1998;98:203742.

10. Alderman MH, Ooi WL, Cohen H, Madhavan S, Sealey JE, Laragh JH. Plasma renin activity: a risk factor for myocardial infarction in hypertensive patients. Am J Hypertens. 1997;10:1-8.

11. Francis GS, Cohn JN, Johnson G, Rector TS, Goldman S, Simon A, for the V-HeFT VA Cooperative Studies Group: Plasma norepinephrine, plasma renin activity, and congestive heart failure: relations to survival and the effects of therapy in V-HeFT II. Circulation 1993;87:VI-40-48.

12. Latini R, Masson S, Anand I, Salio M, Hester A, Judd D, et al. The comparative prognostic value of plasma neurohormones at baseline in patients with heart failure enrolled in Val-HeFT. Eur Heart J. 2004;25:292-9.

13. Rouleau JL, Packer M, Moye L, et al. Prognostic value of neurohumoral activation in patients with an acute myocardial infarction: effect of captopril. J Am Coll Cardiol. 1994;24:58391.

14. Parikh NI, Gona P, Larson MG, Wang TJ, Newton-Cheh C, Levy $\mathrm{D}$, et al. Plasma renin and risk of cardiovascular disease and mortality: the Framingham Heart Study. Eur Heart J. 2007;28:264452

15. Francis GS, Benedict C, Johnston DE, Kirlin PC, Nicklas J, Liang $\mathrm{CS}$, et al. Comparison of neuroendocrine activation in patients with left ventricular dysfunction with and without congestive heart failure. Circulation. 1990;82:1724-9.

16. Pfeffer MA, Braunwald E, Moyé LA, Basta L, Brown EJ, Cuddy TE, et al. The Effect of Captopril on mortality and morbidity in patients with left ventricular dysfunction following myocardial infarction: Results of the survival and ventricular enlargement (SAVE) trial. N Engl J Med. 1992;327:669-77.

17. The Acute Infarction Ramipril Efficacy (AIRE) Study Investigators. Effect of ramipril on mortality and morbidity of survivors of acute myocardial infarction with clinical evidence of heart failure. Lancet. 1993;342:821-8.

18. Køber L, Torp-Pedersen C, Carlsen JE, Bagger H, Eliasen P, Lyngborg K, et al. A clinical trial of the angiotensin-convertingenzyme inhibitor trandolapril in patients with left ventricular dysfunction after myocardial infarction. N Engl J Med. 1995; 333:1670-6.

19. The SOLVD Investigators. Effect of enalapril on survival in patients with reduced left ventricular ejection fractions and congestive heart failure. N Engl J Med. 1991;325:293-302.

20. Cohn JN, Johnson G, Ziesche S, Cobb F, Francis G, Tristani F, et al. A comparison of enalapril with hydralazine-isosorbide dinitrate in the treatment of chronic congestive heart failure. N Engl J Med. 1991;325:303-10

21. Yusuf S, Sleight P, Pogue J, Bosch J, Davies R, Dagenais G. Effects of an angiotensin-converting-enzyme inhibitor, ramipril, on cardiovascular events in high-risk patients. The Heart Outcomes Prevention Evaluation Study Investigators. N Engl J Med. 2000;342:145-53 [HOPE].
22. Sealey JE, Gerten-Banes J, Laragh JH. The renin system: variations in man measured by radioimmunoassay and bio-assay. Kidney Intl. 1972;1:240-53.

23. Nussberger J, Waeber B, Brunner HR. Plasma angiotensin II and the antihypertensive action of angiotensin-converting enzyme inhibition. Am J Hypertens. 1989;2:286-93.

24. Krum H, Carson P, Farsang C, Maggioni AP, Glazer RD, Aknay $\mathrm{N}$, et al. Effect of valsartan added to background ACE inhibitor therapy in patients with heart failure: results from Val-HeFT. Eur J Heart Fail. 2004;6(7):937-45.

25. Campbell DJ, Aggarwal A, Esler M, et al. $\beta$-blockers, angiotensin II, and ACE inhibitors in patients with heart failure. Lancet. 2001;358:1609-10.

26. Packer M, Coats AJ, Fowler MB, Katus HA, Krum H, Mohacsi P, et al. Effect on carvedilol on survival in severe chronic heart failure. N Engl J Med. 2001;344:1651-8 [COPERNICUS].

27. Merit-HF Study Group. Effect of metroprolol CR/XL in chronic heart failure: metroprolol CR/XL Randomised Intervention Trial in Congestive Heart Failure (MERIT-HF). Lancet. 1999;353:2001-7.

28. CIBIS II Investigators and Committees. The Cardiac Insufficiency Bisoprolol Study (CIBIS-II): a randomised trial. Lancet. 1999;353:9-13.

29. McMurray JJ, Pitt B, Latini R, Maggioni P, Solomon SD, Keefe $\mathrm{DL}$, et al. Effects of the oral direct renin inhibitor aliskiren in patients with symptomatic heart failure. Circ Heart Fail. 2008;1:17-24.

30. Oparil S, Yarows SA, Patel S, Fang H, Zhang J, Satlin A. Efficacy and safety of combined use of aliskiren and valsartan in patients with hypertension: a randomised, double-blind trial. Lancet. 2007;370:221-9

31. Pfeffer MA, McMurray JJ, Velazquez EJ, Rouleau JL, Kober L, Maggioni AP, et al. Valsartan, captopril, or both in myocardial infarction complicated by heart failure, left ventricular dysfunction, or both. N Engl J Med. 2003;349:1893-906.

32. The ONTARGET Investigators. Telmisartan, ramipril, or both in patients at high risk for vascular events. $\mathrm{N}$ Engl $\mathrm{J}$ Med. 2008;358:1547-59.

33. Wong M, Staszewsky L, Latini R, Barlera S, Glazer R, Aknay N, et al. Severity of left ventricular remodeling defines outcomes and response to therapy in heart failure. J Am Coll Cardiol. 2004;43:2022-7.

34. Cohn JN, Tognoni G. for the Valsartan Heart Failure Trial Investigators. A randomized trial of the angiotensin-receptor blocker valsartan in chronic heart failure. $\mathrm{N}$ Engl $\mathrm{J}$ Med. 2001;345:1667-75.

35. Julius S, Nesbitt SD, Egan BM, for the Trial of Preventing Hypertension (TROPHY) Study Investigators, et al. Feasibility of treating prehypertension with an angiotensin-receptor blocker. $\mathrm{N}$ Engl J Med. 2006;354:1685-97.

36. Duprez DA, Florea ND, Jones K, Cohn JN. Beneficial effects of valsartan in asymptomatic individuals with vascular or cardiac abnormalities: The DETECTIV Pilot Study. J Am Coll Cardiol. 2007;50:835-9. 